\title{
Dinámicas de poder y dimensión simbólica en los conflictos del extractivismo agrario en Argentina
}

\author{
Erika Judith Barzola \\ CIECS-CONICET-UNC; Universidad siglo 21. Córdoba, Argentina. \\ Email: erijbarzola@hotmail.com
}

Resumen: En el presente escrito nos interesa realizar un análisis del conflicto que enfrentó a los vecinos de Malvinas Argentinas con la multinacional Monsanto, a fin de reflexionar sobre las dinámicas del poder que posibilitan o niegan el acceso y la toma de decisiones sobre los bienes comunes y los territorios y sobre la dimensión simbólica que se pone en juego y se enfrenta al extractivismo agrario en Argentina. No podemos reflexionar sobre estos aspectos sin considerar que el proyecto moderno implicó el ejercicio de un biopoder sobre la naturaleza y sobre los cuerpos humanos subalternizados (Alimonda, 2011). Metodológicamente nos enmarcamos en el paradigma interpretativo y desarrollamos una investigación de corte cualitativo, haciendo uso de entrevistas en profundidad y análisis sociológico del discurso. Concluimos este escrito considerando los logros de los vecinos, pero también resaltando la imposibilidad de consolidarse en el tiempo como movimiento social contra la hegemonía del sistema extractivo.

Palabras Claves: Lucha socio-ambiental; repertorios de resistencia; lenguajes de valoración; agronegocio.

\section{The dynamics of power and symbolic dimension in the agro-extractive conflict over Monsanto's installation in the Argentine Malvinas}

\begin{abstract}
In this paper, we are interested in analyzing the conflict between the neighbors of the Argentine Malvinas (Falklands) and the multinational Monsanto, in order to reflect on the dynamics of power that enable or deny access and decision-making on common goods and territories and on the symbolic dimension that is at stake and confronts agrarian extractivism in Argentina. We cannot reflect on these aspects without considering that the modern project implied the exercise of a biopower over nature and subalternized human bodies (Alimonda, 2011). Methodologically, we followed the interpretative paradigm and developed a qualitative research, employing in-depth interviews and sociological analysis of the discourse. We conclude this paper considering the achievements of the neighbors, but also highlighting the impossibility of consolidating in time as a social movement against the hegemony of the extractive system.
\end{abstract}

Keywords: Social-environmental struggle; repertoires of resistance; valuation languages; agribusiness.

\section{Dinâmica de poder e dimensão simbólica nos conflitos do extrativismo agrário na Argentina}

Resumo: No presente documento estamos interessados em realizar uma análise do conflito que confrontou os moradores das Malvinas Argentinas com a multinacional Monsanto, a fim de refletir sobre as dinâmicas de poder que permitem ou negam o acesso e a tomada de decisão sobre bens comuns e os territórios e na dimensão simbólica que é posta em jogo e confronta o extrativismo agrícola na Argentina. Não podemos refletir sobre esses aspectos sem considerar que o projeto moderno envolveu o exercício de um biopoder sobre a natureza e sobre corpos humanos subalternizados (Alimonda, 2011). Metodologicamente, nos encaixamos no paradigma interpretativo e desenvolvemos pesquisas qualitativas, utilizando entrevistas em profundidade e análises sociológicas do discurso. Concluímos está escrita considerando as conquistas dos vizinhos, mas também destacando a impossibilidade de se consolidar no tempo como um movimento social contra a hegemonia do sistema extrativista. 
Palabras-chave: Luta socioambiental; repertórios de resistência; linguagens de avaliação; agronegócio.

\section{Introducción}

El presente artículo surge como parte de una investigación que se viene desarrollando desde 2013. En una etapa inicial de este trabajo (2013-2015) se indagó por las representacionesde los miembros de los diversos movimientos sociales y organizaciones de la sociedad civil, de la ciudad de Córdoba -Argentina, en torno a las políticas públicas ambientales. Estos movimientos sociales y organizaciones de la sociedad civil fueron escogidos intencionalmente por el trabajo territorial de resistencia frente las consecuencia de la extensión del modelo extractivista agrícola. Concretamente estos movimientos y organizaciones resistían al desmonte en zonas de alto valor de conservación del monte nativo, a las pulverizaciones con agrotóxicos en inmediaciones de zonas urbanizadas y a la instalación de una planta de tratamiento de semillas de la firma Monsanto dentro del ejido municipal de la localidad de Malvinas Argentinas, provincia de Córdoba-Argentina. En una segunda etapa del trabajo (2015- a la actualidad), nos hemos centrado en el conflicto que enfrentó a los vecinos de la localidad de Malvinas Argentinas con la multinacional Monsanto y nos estamos preguntando por las tensiones y disputas democráticas, así como por los diferentes lenguajes de valoración, que plantea la intervención de empresas transnacionales en el ámbito del territorio local, en el marco de la extensión del modelo extractivista agrícola en Argentina.

Tomando como referencia lo señalado, en el presente escrito nos interesa realizar un análisis del conflicto que enfrentó a los vecinos de Malvinas Argentinas, nucleados en la asamblea Malvinas Lucha por la Vida, con la multinacional Monsanto, a partir de las herramientas teóricas que nos ofrece la ecología política. La lucha de Malvinas Argentinas implicó un punto de inflexión en las luchas socioambientales de Argentina, ya que los vecinos no sólo se enfrentaron a la empresa paradigmática del extractivismo agrícola, las semillas transgénicas y la propiedad del material genético, sino que además desafiaron y resistieron la transversalidad política propia del modelo extractivista agrícola (Savampa y Viale, 2014). Por esta razón, consideramos que el conflicto en cuestión permite, en primer lugar, reflexionar sobre las dinámicas del poder, que al decir de Alimonda (2011), posibilitan el acceso y la toma de decisiones sobre los bienes comunes y los territorios a determinados actores con influencia económica y política, yniegan a otros la posibilidad de disponer de su lugar y de decidir al respecto. En segundo lugar, el mencionado conflicto nos permite comprender la dimensión simbólica que se pone en juego y se enfrenta al extractivismo agrario en Argentina, a partir de analizar los diferentes lenguajes de valoración que se tensionan, resignifican, apropian y se construyen en contextos conflictivos frente al despojo, al saqueo y a la acumulación por desposesión.

A fin de dar cuenta de lo señalado, proponemos una estructura argumental que comienza con una contextualización de las modificaciones que ha sufrido el agro argentino en las últimas décadas. Consideramos que este aspecto es central para comprender la lógica de acumulación por desposesión, acaparamiento y saqueo en el que se inserta el conflicto bajo análisis. Seguidamente nos centraremos en el análisis del caso de estudio, haciendo un recorrido histórico y analítico pretendiendo, como adelantábamos, reflexionar sobre las dinámicas de poder y la dimensión simbólica que se plasma en contextos de resistencia frente al extractivismo agrario. Finalmente, exponemos a modo de consideraciones finales algunos puntos de reflexión en materia de logros y limitaciones de las luchas sociales contra el saqueo y el despojo, procurando con ello ampliar y enriquecer un debate académico y político que tienda a fortalecer a los movimientos insurgentes contra el capital extractivo.

\section{Metodología}

La investigación que da origen a este escrito se inserta en el paradigma interpretativo ya que "nos interesamos en las formas en las que el mundo social es interpretado, comprendido, experimentado y producido" (Vasilachis de Gialdino 2007, p. 25). Al posicionarnos dentro de este paradigma partimos del supuesto ontológico que versa en la construcción social de la realidad. Consideramos que la realidad social es construida no solo por 
las acciones de las personas, sino también por los significados compartidos e interpretados mediante la interacción social. Desde esta perspectiva paradigmática desarrollamos una investigación de corte cualitativo.

La principal técnica de recolección de datos que utilizamos es la entrevista en profundidad, cuyo dinamismo y flexibilidad posibilitan la construcción conversacional entre el investigador y el entrevistado (Merlino 2012). En el marco de la primera etapa del trabajo investigativo, el universo de estudio fueron los sujetos que pertenecían a algún movimiento social u organización de la sociedad civil de la ciudad de Córdoba, que resistieran las consecuencias la extensión del modelo extractivista agrícola. En el marco de la segunda etapa de trabajo, nos centramos en los vecinos de la Ciudad de Malvinas Argentinas, nucleados en la asamblea Malvinas Lucha por la Vida y en los funcionarios públicos del municipio de Malvinas Argentinas y de la secretaría de ambiente de la provincia de Córdoba. En ambos casos, el muestreo teórico nos permitió la selección de los casos a estudiar en función de la potencialidad que estos ofrecían para profundizar o ampliar las categorías que se iban desarrollando con el devenir de la propia investigación. Además, este muestreo nos posibilitó trabajar con la noción de saturación teórica, dando por concluido el muestreo cuando la incorporación de un nuevo caso de estudio no aportaba información adicional a fin de desarrollar nuevas propiedades de las categorías con las que se estaba trabajando (Vasilachis de Gialdino, 2007). En la primera fase de trabajo, la muestra quedó conformada por un total de 14 personas. En tanto que en la segunda instancia, la muestra fue de 18 casos.

Sumado a lo dicho, en la segunda etapa de investigación, además de entrevistar a los miembros de la asamblea Malvinas Lucha por la Vida, se realizó un análisis sociológico del discurso de las noticias publicadas en el diario La Voz del Interior ${ }^{1}$, durante 2012 y 2016. La principal razón por la que se decide tomar estas noticias radica en la posibilidad que las mismas otorgan para analizar la construcción de sentidos y los diferentes lenguajes de valoración en disputa en el marco del conflicto bajo análisis. El recorte temporal de la selección, deviene del ciclo de conflictividad, el cual inicia en julio de 2012 y finaliza en octubre de 2016. El corpus de análisis está compuesto de 250 artículos.

\section{Las modificaciones del agro argentino en las últimas décadas}

Nos resulta innegable pretender reflexionar sobre las modificaciones que atraviesa el agro argentino en las últimas décadassin poner en consideración queel surgimiento de la modernidad -a partir de la conquista de América- y su reverso necesario y oculto -la colonialidad- supuso para el continente no sólo una catástrofe socio-cultural, económica, política y ambiental (Escobar, 2011; Alimonda, 2006), sino que, además, implicó que la región ocupase un lugar de sacrificio en la geopolítica mundial, a partir de entender que lo latinoameri-

cano se constituyó según una relación de colonialismo y dominación con un global hegemónico (Alimonda, 2006). En palabras de Alimonda:

El proyecto moderno implicó siempre el ejercicio de un biopoder sobre la naturaleza, entendido como poder sobre los espacios físicogeográficos, los suelos y los subsuelos, los recursos naturales, flora y fauna, el aprovechamiento de las condiciones climáticas, pero también poder sobre los cuerpos humanos subalternizados por la dominación. La biopolítica de los discursos moderno/coloniales no produce solamente subjetividades y territorialidades, produce también 'naturalezas', es decir, pone en evidencia la colonialidad de las naturalezas (2011: 52)

En otras palabras, estos procesos formaron parte de un dispositivo de poder que permitió una reterritorialización de la región, en función de una lógica de economía de rapiña² (Alimonda, 2006), que constituyó a la naturaleza en mercancía. Dicho de otra manera, en la modernidad, la naturaleza se transformó en objeto de dominio, de conocimiento y de materia prima del proceso productivo, desnaturalizándola e insertándola como un recurso en la lógica del valor de cambio y de la productividad económica (Leff, 2006). Polanyi (2007), plantea que la naturaleza fue reducida sólo a tierra, lo que significó no sólo su mercantilización, sino lo que Woster (2008) entiende como un proceso de reorganización integral de la agricultura. Es decir, una reestructuración de los sistemas agroecológicos promovidos por el capitalismo con el propósito de intensificar la producción de alimentos y la acumulación de capital (Woster, 2008). 
En este contexto, luego de la segunda guerra mundial, América Latina fue inscripta como una región proveedora de alimentos a nivel mundial. Para ese entonces, la lucha contra el hambre se transformó en la nueva meta del occidente capitalista y, según Escobar (2007), la invención del tercer mundo fue la vía privilegiada para que los países centrales pudiesen formular y aplicar políticas tendientes a resolver los problemas del tercer mundo. En este marco, la llamada revolución verde ${ }^{3}$ resultó ser la vía por excelencia para resolver las demandas mundiales de alimentos. Para el caso de Argentina, la tecnificación y modernización de la agricultura llegó en la década de los '70 promovida por el Instituto Nacional de Tecnología Agropecuaria (INTA ${ }^{4}$ ). Para ese entonces, en el país, se dejó de alternar la producción agrícola con la ganadera y se abrió paso a una agriculturización, basada en dos cosechas por año gracias a las cosechas de segunda y a la alternancia que la misma permite desarrollar entre soja y trigo (Teubal, 2006). A partir de entonces, Argentina emergió como un nuevo país agropecuario sustentando la actividad en el cultivo de soja y en el paquete tecnológico que la acompañaba (Teubal, 2006). Esta transformación terminó de consolidarse en la década de los '90 de la mano del decreto de Desregulación Económica (2284/91) que implicó cambios en las políticas del sector y eliminó una serie de organismos Nacionales (Junta Nacional de Granos y Carnes, precio sostén, etc.) que desde la década del '30 venían actuando como órganos de control (Teubal, 2006; Barri y Wahren, 2010). Esto posibilitó que en el año 1996 la Secretaría de Agricultura y la Comisión Nacional Asesora de Biotecnología Agropecuaria (CONABIA) autorizaran la introducción y su correspondiente utilización de soja transgénica, comercialmente llamada RR -Roundup Ready-, junto con el paquete tecnológico necesario para su producción (Teubal, 2006; Barri y Wahren, 2010; Carrasco, Sánchez y Tamagno, 2012). Con el devenir de los años el uso de este paquete tecnológico se hizo extensivo y se generó lo que algunos autores (Barri y Wahren, 2010; Carrasco, Sánchez y Tamagno, 2012; Giarraca y Teubal, 2013) denominan sojización, es decir, la expansión del cultivo de soja en toda la región pampeana y la extensión de la frontera agrícola hacia otras zonas del país.

De la mano de la sojización y como una segunda oleada de la revolución verde, a partir de la década del 2000, se instala definitivamente en Argentina el modelo productivo agrícola de agronegocio, que apunta a controlar la producción, el almacenaje, procesamiento y comercialización, tanto de las semillas, como de sus productos derivados, lo que facilita la consolidación de oligopolios (Teubal, 2006) y termina de desplazar a las comunidades indígena-campesinas como principales actores del mundo rural, abriendo paso a los grandes pooles de siembra.

Desde la perspectiva que adoptamos en este trabajo, entendemos que el agronegocio debe ser abordado críticamente, para interpelar el lugar de naturalización en el que lo han intentado colocar discursivamente las grandes hegemonías mundiales, a fin de desentrañar las consecuencias que este modelo genera a nivel social, político, económico y ambiental. Advertimos que el modelo de agronegocio, antes que nada, es un modelo extractivo basado principalmente en una acumulación por desposesión (Harvey, 2004). Boaventura de Sousa Santos (2009) explica que esta lógica de acumulación se inscribe en una suerte de fascismo territorial que se enmarca en una nueva forma de colonialismo, que afecta directamente al campesinado y asume una virulencia alarmante en la actualidad, trasformando la actividad agrícola en meras plataformas productivasimplantadas en los países del Cono Sur, que orientan sus actividades a la satisfacción de las necesidades estratégicas de abastecimiento de las grandes corporaciones globales (Gras y Hernández, 2013). En otras palabras, el modelo extractivo, basado en la acumulación por desposesión, se encuentra atravesado fuertemente por una colonialidad del poder y del saber (Lander, 2011) “que se vislumbra como uno de los pilares de la configuración social que sostienen la renta en la periferia” (Giarraca y Teubal, 2013, p.71) y que se presenta como el motor del crecimiento económico regional (Seoane, 2013). Dicho crecimiento, en vez de posibilitar un desarrollo genuino pone en juego una lógica de ocupación destructiva de los territorios y una desacumulación y despojamiento, debido a la permanente reaparición de la acumulación originaria de las potencias hegemónicas (Gras y Hernández, 2016).

En el caso de Argentina, el crecimiento económico suscitado durante el período 2003-2007 se encontró estrechamente asociado con la venta de commodities al exterior, lo que da cuenta de la profundización de las políticas estatales tendientes a consolidar la matriz extractivista. Por ejemplo, en 2011 el gobierno nacional anunció el Plan Estratégico Agroalimentario y Agroindustrial 2010-2020, que se mantiene vigente hasta nuestros días, y prevé un incremento en la producción de granos. Esta meta va de la mano con la autorización del Ministerio de Agricultura, Ganadería y Pesca de la comercialización de una nueva semilla de soja transgénica, 
la Intacta RR2 Pro, de Monsanto. Medida que coincide con la decisión de la transnacional de instalar una planta de tratamiento de semillas en la localidad de Malvinas Argentinas-Córdoba (Seoane, Taddei y Algranati, 2013). En relación al rol de los gobiernos Nacionales en el fortalecimiento de la matriz extractivista, coincidimos con Taddei quien señala que, si bien

“el kirchnerismo contribuyó a consolidar fuertemente esta matriz, la promoción y profundización del extractivismo agrario-exportador fue ratificada por el actual presidente Mauricio Macri a pocos días de iniciado su mandato. Durante el acto de anuncio de la reducción de las retenciones a las exportaciones agrícolas el presidente señaló a los representantes de los productores agrarios que 'Tenemos que dejar de ser el granero del mundo para pasar a ser el supermercado del mundo. Estoy apostando a la capacidad que tienen de crecer, de duplicar la producción agropecuaria del país’” (Taddei, 2016, p. 18).

Estas voluntades políticas no hacen otra cosa que evidenciar y consolidar la díada colonialismo-capitalismo, la que puede explicarse por el poder que las empresas transnacionales ejercen sobre las leyes y normas nacionales, ajustándolas a sus intereses particulares. En palabras de Boaventura de Sousa Santos (1998), presenciamos un globalismo localizado, ya que el impacto de los imperativos transnacionales desestructura y reestructura los contextos locales en función de los intereses globales.

Esta desestructuración y reestructuración conlleva implícitamente un doble ocultamiento: por un lado, el de aquellas actividades, maneras de pensar, sentir y vivir que escapan al pensamiento hegemónico y que deben sacrificarse en pos del desarrollo (Giarraca y Teubal, 2013). La tecnificación y modernización de la agricultura modificó drásticamente las relaciones sociales de producción y obligó a las comunidades campesinas e indígenas a someterse a los requerimientos de las grandes empresas multinacionales que promovían este nuevo modelo de producción en el ámbito agrario (Teubal, 1984), lo que las condenó a la extinción y marginación. Tal como lo habían anticipado los técnicos de Naciones Unidas en la década del '50, el desarrollo era imposible sin ajustes dolorosos y aquellas filosofías ancestrales y viejas instituciones sociales tenían que ser erradicadas, al tiempo que grandes masas de personas incapaces de seguir el ritmo del progreso deberían ver frustradas sus expectativas de una vida cómoda (Naciones Unidas, 1951: I cit. en Escobar, 2007). Por otro lado, la desestructuración y reestructuración conlleva implícito el ocultamiento de las externalidades propias de la lógica extractivista.

De esta manera, el sistema se apropia de los discursos de pueblo y comunidades que han vivido en armonía con su entorno y re-significa sus prácticas, tornándolas arcaicas e improductivas. Se consolida así un modelo de desarrollo basado en la explotación de los bienes comunes como mercancía, que no internaliza los costos sociales, económicos, políticos y ambientales que la propia actividad supone, transformándose en el principal responsable de la desarticulación de los tejidos sociales, ancestrales y comunitarios sobre los que se asentaba la ruralidad en nuestra región.

En consecuencia, si la clave en la economía de mercado es la transformación de la naturaleza en mercancía, las luchas de resistencia contra estos procesos no pueden entenderse en nombre de la negación del progreso. Estas luchas deberán comprenderse como "formas de resistencia basadas en la defensa de sistemas tradicionales de organización social para el uso y disposición comunitaria de los recursos humanos y naturales, frente a los embates de la mercantilización” (Alimonda, 2011, p.39).

\section{David vs. Goliat}

Malvinas Argentinas es una localidad de 12581 habitantes $^{5}$, que se encuentra ubicada en el departamento Colón, a escasos $12 \mathrm{Km}$ de la ciudad de Córdoba. Se une a ella y a la ciudad vecina de Monte Cristo mediante la ruta provincial A88 y la ruta nacional 19. La localidad, surgida como paraje ferroviario (Estación Kilómetro 711), actualmente se encuentra dividida en tres secciones: al norte, cruzando la ruta A 88, se encuentra la $1^{\circ}$ sección; entre las mencionadas arterias se halla la $2^{\circ}$ sección; y al sur de la ruta nacional 19 se emplaza la $3^{\circ}$ sección. 
Antiguamente, la región se caracterizaba por ser una zona de montes de churquis, chañar, algarrobo y piquillín que proveían de leña y carbón a la ciudad (Municipalidad de Malvinas Argentinas, 2006). No obstante, en la actualidad, el paisaje de la zona, el uso de la tierra y el tipo de actividad productiva han cambiado. Por estos días, en inmediaciones de Malvinas Argentinas se pueden observar, por un lado, campos cultivados con soja, los que en un gran porcentaje corresponden a productores y arrendatarios de Monte Cristo y en baja proporción a productores locales. Por otro lado, en cercanías de la comunidad hay un área industrial (sobre la ruta 19) en la que se sitúa un escaso número de industrias.

Durante el período comprendido entre 2001 y 2008 la población de Malvinas Argentinas creció aproximadamente un $75 \%$, debido a un fuerte flujo migratorio de habitantes de la ciudad de Córdoba. El incremento poblacional, sumado a las escasas fuentes de trabajo, generó una situación social vulnerable para gran parte de sus habitantes. En el año 2008, 2/3 de la población se encontraban desempleada (el 36\% de la población económicamente activa) o con un trabajo precarizado (Ávila Vázquez, 2013). La población femenina económicamente activa que se encontraba empleada realizaba sus labores en el ámbito público o como empleadas domésticas en la ciudad de Córdoba Capital. Por su parte, los hombres trabajaban en la construcción y mantenimiento edilicio (servicios no permanentes de albañilería, plomería, cerrajería, electricidad), en la industria automotriz y en los cortaderos de ladrillos cercanos. Para ese entonces, un $25,7 \%$ de los hogares tenían Necesidades Básicas Insuficientes (NBI) y el 70.4\% de la población no tenía cobertura de obras sociales.

Según un informe publicado en Diciembre del 2010 por el diario La Voz del Interior, los datos censales indicaban que

"El promedio provincial de hogares con al menos una NBI es del 6,6 por ciento. En todo el territorio cordobés hay 427 localidades y 240 de ellas superan ese porcentaje, por lo que el 56 por ciento de las ciudades y pueblos sufre de lo que se podría llamar 'pobreza grave'. Si se tienen en cuenta las ciudades con más de 10 mil habitantes, las peores están muy cerca de la ciudad de Córdoba. Encabeza el ranking Malvinas Argentinas, con casi el 20 por ciento de NBI”6.

En relación a las NBI, es menester resaltar que la comunidad de Malvinas Argentinas no posee agua corriente, no todas las secciones del poblado cuentan con red de gas domiciliaria, que llega solamente al 30\% de la ciudad y del parque industrial, y la localidad no posee red cloacal. Sumado a esto, en general, las familias malvinenses son numerosas, tienen entre tres y cinco hijos más que las familias tipo de Argentina. En materia educativa, la mayor parte de su población sólo cuenta con el primario completo como máximo nivel de instrucción alcanzado y un reducido número de habitantes posee un nivel de instrucción universitario o superior, pese a la cercanía de la localidad con la ciudad de Córdoba (Ávila Vázquez, 2013).

A mediados del 2012, se comunicó una inversión millonaria con sede en la comunidad de Malvinas Argentinas, tendiente a incrementar las fuentes de trabajo en la localidad. El día 15 de junio de 2012, a sólo 3 días de iniciado el juicio por contaminación en barrio Ituzaingó Anexo ${ }^{7}$, la presidente Cristina Fernández de Kirchner anunció que la multinacional Monsanto invertiría más de 1.500 millones de pesos para construir una planta de acondicionamiento de semillas de maíz y una estación experimental en la comunidad. En el almuerzo con el Council de las Américas en Nueva York, la presidente manifestaba:

"Aquí tengo - y esto la verdad que se los quiero mostrar porque estoy muy orgullosa - el prospecto de Monsanto. Vieron que cuando hacen prospecto es porque ya está hecha la inversión, sino no te hacen prospecto. Así que una inversión muy importante en Malvinas Argentinas, en la provincia de Córdoba, en materia de maíz con una nueva, digamos, semilla de carácter transgénico, que se llama Intacta. También dos centros de investigación y desarrollo, que eso para nosotros es tan importante como es esta inversión de 150 millones de dólares: uno, en Tucumán y otra en la misma Córdoba, porque estamos trabajando mucho con científicos” (el resaltado es nuestro) ${ }^{8}$.

Dos días después del anuncio de la Presidente, el Gobernador de la Provincia, José Manuel de la Sota, proclamaba la inversión de la firma alemana Class en la comunidad de Oncativo y ratificaba la inversión de 
Monsanto por 1.500 millones de dólares en la localidad de Malvinas Argentinas. En dicha ocasión, el mandatario declaraba:

"Una de las empresas va a estar en Malvinas, acá cerquita, [...] va a dar una cantidad de puestos de trabajo importante, vinculada a la producción de semillas de alta calidad para mejorar los rindes agropecuarios, esta planta va a ser la más importante de América Latina. Son empresas relacionadas con el agro negocio, que para Córdoba es fundamental, es la mayor fuente de riqueza de la provincia” (el resaltado es nuestro) ${ }^{9}$

Por su parte, el entonces Ministro de Industria, Comercio y Minería, Jorge Lawson, indicaba:

"Esta provincia es un lugar donde respetamos claramente las actividades empresariales [...] Nosotros no discutimos las políticas nacionales; tenemos una visión y el desarrollo empresarial es una parte importante de nuestra gestión. La verdadera inclusión social es dar a los ciudadanos posibilidades de tener un trabajo digno" (el resaltado es nuestro) ${ }^{10}$.

El día 13 de julio, sin contar con la pre-factibilidad del proyecto aprobado por la Secretaría de Ambiente Provincial, la municipalidad de Malvinas Argentinas sancionó, en sesión extraordinaria, la ordenanza $\mathrm{N}^{\circ}$ 808/ 2012 por medio de la que se aprobaron las obras preliminares en el predio en el que se instalaría Monsanto. En sus primeras declaraciones mediáticas y en consonancia con los dichos del Ministro de Industria, Comercio y Minería, el intendente de Malvinas Argentinas, defendía la llegada de Monsanto a su comunidad y destacaba la generación de empleo que traería aparejada la planta de tratamiento de semillas de la firma estadounidense. Sumado a esto, el mandatario se (pre)ocupaba de aclarar que el municipio iba a ser estricto en el cumplimiento de la lay a fin de evitar contaminación en el poblado.

"Vamos a trabajar codo a codo con Medio Ambiente de la Provincia. No vamos a ceder en absolutamente nada. La ley se aplicará tal cual es, tanto con esta empresa como con toda otra que se instale al pueblo [...] Habrá un control permanente de lo que se haga en este pueblo. No vamos a permitir que nadie nos venga a contaminar" (el resaltado es nuestro) ${ }^{11}$

Estos hechos, por un lado, demuestran que las acciones legislativas emprendidas, principalmente por el municipio de Malvinas Argentinas, contradecían los dichos del intendente y lo instituido por la Ley General de Ambiente $\mathrm{N}^{\mathrm{o}}$ 25675. La mencionada ley, en su artículo $4^{\circ}$, instaura el principio precautorio y el principio de congruencia. El principio precautorio establece que cuando haya peligro de daño grave o irreversible en el ambiente, la falta de certeza sobre dichos daños no debe ser limitante para impedir la toma de medidas tendientes a evitar que ese daño se produzca. El principio de congruencia plantea que las leyes ambientales del nivel provincial y municipal deben adecuarse a lo establecido en la Ley General de Ambiente y, cuando así no lo hiciesen, esta ley prevalecerá por sobre las normativas de menor jerarquía que se le opongan (Ley General del Ambiente, 2002).Ambos principios no fueron considerados por el concejo deliberante del Municipio de Malvinas Argentinas, ya que los ediles municipales aprobaron las obras preliminares de construcción de la planta de tratamiento de semillas de maíz sin un estudio de impacto ambiental que determinase el nivel de daño que dicha planta pudiese generar. Al tiempo que se amparaban en la ley provincial de ambiente, la que no estaba adecuada a la ley nacional.

Por otro lado, evidencia la anuencia de los tres niveles del Estado para que Monsanto se instalase en la comunidad de Malvinas Argentinas, demostrando la alianza hegemónica (Antonelli, 2010)multiescalar que la empresa sostenía con los diferentes estamentos de gobierno, aun cuando éstos fuesen liderados por partidos políticos opositores.Esto no hace más que demostrar el colonialismo y la dependencia de los estados nacionales para con las empresas multinacionales, quienes detentan el poder de incidir en políticas estatales con el fin de hacer plausible sus capacidades de configurar territorialidades, subjetividades y naturalezas acorde a sus intereses de acumulación capitalista. En palabras de Machado Aráoz (2011), se evidenciaría una democracia colonial, es decir el accionar de los gobiernos representativos, quienes asumen como propios los modelos desarrollistas de los inversores, aún a expensas de la voluntad de la población. 
El anuncio de la presidente y del gobernador provincial despertó el interés de los vecinos de Malvinas Argentinas, quienes comenzaron a interiorizarse sobre Monsanto, sus productos y el proyecto que se instalaría en su comunidad. Al respecto, una entrevistada mencionaba:

"Nos enteramos por la tele que se instalaba Monsanto en nuestro barrio y entonces decidimos organizarnos, preocupados, algunos sabemos un poco más, otros un poco menos de lo que era Monsanto, algunos no sabían nada pero, bueno como que en seguida se tornó un tema muy importante en el barrio” (Vanesa, estudiante, 23 años)

Los vecinos de Malvinas Argentinas se reunieron por primera vez el día 24 de julio, para interiorizarse sobre la instalación de la empresa en su comunidad. A dicha reunión, de la que participaron alrededor de 200 personas, asistió como invitado experto el Dr. Raúl Montenegro, biólogo presidente de la Fundación para la Defensa del Medio Ambiente (FUNAM). Según se desprende del relato de nuestros entrevistados,

"Raúl Montenegro explicó con detalles cuál es la producción de Monsanto y, y no solamente eso sino también el aspecto político digamos, las políticas que, con las que Monsanto se mueve en todo el mundo a nivel global y, y bueno ese mismo decidimos que teníamos que volver a juntarnos” (Vanesa, estudiante, 23 años)

A medida que avanzaban las reuniones vecinales y convencidos de que debían actuar colectivamente, en la tercera reunión llevada a cabo el día 31 de julio los vecinos decidieron conformar la Asamblea de Vecinos Malvinas Lucha por la Vida. La conformación de la asamblea marca un hito en la historia política de la localidad. Antes de la llegada de Monsanto, Malvinas Argentinas se caracterizaba, según nuestros entrevistados, por ser una comunidad con un debate político muy clausurado y una ciudadanía con baja participación. No obstante, frente a la percepción del riesgo que suponía la instalación de la multinacional“los vecinos que nunca habían salido, empezaron a definir que era necesario organizarse" (Cecilia, estudiante, 32 años).Esto conllevó a que los vecinos abandonasen el espacio privado para comenzar a ocupar el espacio público, lo que potenció su actuar político.Este cambio-ruptura de dejar de ser y pasar a hacer, tuvo fuertes implicaciones en la construcción deuna subjetividad política colectiva.Los propios entrevistados señalan que hubo un fuerte trabajo de construcción del sujeto vecino como sujeto político, lo que les posibilitó por una parte, incrementar la legitimidad de su reclamo frente a la ciudadanía ampliada y por otra parte, ubicarse como actor legítimo en el conflicto desencadenado, constituyéndose como sujeto susceptible de hacer y decirse.

Será en consecuencia, el sujeto político vecino el que encarne diversos repertorios de resistencia y discursivos, concatenados y relacionados unos con otros, en el marco de la lucha desencadenada. En lo que respecta a los repertorios de resistencia, al inicio del conflicto recurrieron a repertorios no disruptivos, anclados en un marco institucional formal, buscando por vía legislativa y jurídica tomar el poder del estado. En palabras de uno de nuestros entrevistados

"tomar el poder del estado implicaba hacer que el estado, las instituciones, jugaran a favor del objetivo, de lo que nosotros sentíamos y creíamos que era justo, a favor de nuestros intereses, entonces tomar el poder del estado implicaba dar la batalla institucional” (Víctor, docente, 41 años).

Si bien fueron variados los repertorios desarrollados en el marco de esta vía (imputaciones, amparos, denuncias, pedidos de información pública al municipio y la secretaría de ambiente, etc.), se pueden destacar dos acciones que a nuestro entender son de relevancia no sólo para la lucha, sino para sostener la construcción del sujeto político, la legitimidad social y los repertorios discursivos que estaban construyéndose, tensionándose y poniéndose en juego.

La primera acción que quisiéramos remarcar, consistió en la presentación de un proyecto de ordenanza por iniciativa popular, que procuraba la ampliación de la zona de resguardo ambiental, considerando 2500 metros del ejido urbano y 5000 de instituciones educativas y sanitarias y la creación de un órgano de control para las fumigaciones tanto permitidas como ilegales. Dicho proyecto fue rechazado por el concejo deliberante de la municipalidad en dos ocasiones, la primera de ellas por carecer de la firma de 10 promotores de la 
ordenanza, la segunda por contar con deficiencias de forma, desconociendo la importancia de los aspectos de fondo.

La segunda acción,que se trasformó en uno de los lemas y bandera de la lucha que libraban los vecinos, fue el petitorio de la realización de una consulta popular:

"queremos un voto secreto, para que la gente no pueda ser sancionada...queremos voto secreto, no queremos los mismos mecanismos de 1880/90, queremos el voto secreto para no permitir, sobre todo en las pequeñas comunidades, la coerción que tienen los políticos sobre los vecinos” (Víctor, docente, 41 años).

Por medio de este mecanismo participativo, previsto en el artículo 20 de la Ley General del Ambiente, la asamblea Malvinas Lucha por la Vida pretendía que todos los habitantes de la ciudad pudiesen expresar su voluntad sobre la radicación de Monsanto.

La demanda de implementación de esta herramienta trajo consigo múltiples debates al interior de la asamblea, dado que había miembros que temían a un posible resultado adverso, lo que hubiese clausurado la lucha. Este temor se amparaba fundamentalmente en que, el por entonces intendente de la localidad, había ganado la intendencia por cuarta vez consecutiva con un $80 \%$ de los votos. En palabras de nuestros entrevistados, esto había sido posible dado a los manejos clientelares y paternalistas que se evidenciaban desde la gestión municipal, aspecto que también era temido a la hora de solicitar la consulta popular. No obstante lo dicho, los vecinos nucleados en la asamblea, consideraron que en democracia, era una estrategia de sumo valor, dado que una negativa al derecho al voto automáticamente colocaba la gestión municipal como antidemocrático.

Estos repertorios de resistencia, al no haber tenido una respuesta o haber obtenido una respuesta negativa por parte de los estamentos del estado a quienes iban dirigidos, posibilitaron que, avanzado el conflicto, se pudiesen implementar mecanismos de resistencia disruptivos, sin perder el apoyo y la legitimidad que había adquirido la lucha de los vecinos. Tal es así que al cabo de un año de resistencia, la asamblea Malvinas Lucha por la Vida, decide iniciar un bloqueo en el predio en donde pretendía instalarse Monsanto. El propósito de este bloqueo era impedir que ingresasen materiales para construir la planta. Bajo la excusa de organizar un festival cultural al que denominaron primavera sin Monsanto, los miembros tomaron posesión del ingreso al predio.

Esta acción se extendió por más de 3 años consecutivos y generó disputas y quiebres al interior de la asamblea. El primer momento de tensión entre los vecinos devino estrictamente a la hora de decidir sobre la realización del bloqueo o no. Había miembros que consideraban que era una estrategia de resistencia que no iba a poderse sostener en el tiempo. $\mathrm{Al}$ respecto, un entrevistado nos mencionaba:

"nosotros no tenemos espalda los vecinos que somos acá, porque con el correr del tiempo ganábamos en adhesión pero perdíamos en cuerpos, ganar una adhesión y perder cuerpos...perdimos cuerpo en la resistencia porque empieza a operar todo el aparato del estado en un pueblo como Malvinas” (Víctor, docente, 41 años).

El segundo momento de tensión entre los miembros de la asamblea se produce con posterioridad a que la Secretaría de Ambientede la Provincia de Córdoba rechazase el estudio de impacto ambiental (EIA) que había presentado Monsanto. Ante esta situación, con un amparo de la justicia provincial que impedía la construcción de la fábrica hasta tanto la secretaría de ambiente no se expidiese en relación al EIA y con un rechazo de éste por parte del organismo competente, una facción de los miembros de la asamblea consideraban que ya no era necesario seguir sosteniendo el bloqueo. En tanto otro grupo planteaba que debían permanecer a la vera del predio hasta tanto Monsanto retirase sus pertenencias de manera definitiva. Este quiebre, sumado a la presencia de grupos anarquista en el bloqueo, quienes terminan por desconocer a la asamblea como referente de la lucha, terminó de consolidar la división entre los vecinos, generándose dos asambleas: la asamblea de origen que mantuvo el nombre de Malvinas Lucha por la Vida y la nueva asamblea que se desprende de ésta, que se autodenomina Malvinas Lucha por la Vida - Línea Fundadora. 
Estos quiebres y divisiones pueden explicarse por variados motivos, en primer lugar hay que comprender que la lucha duró más de 4 años, y que el estado - en sus diferentes estamentos-, así como la empresa, emprendieron diversas estrategias con el fin de debilitar y quebrantar la lucha y la resistencia. Los medios de comunicación masivos y las operaciones mediáticas constantes que buscaban desclasificar el accionar de los vecinos, es otro factor de incidencia.

Llegado el 2015, año electoral, con un revés judicial y otro administrativo para Monsanto, la asamblea Malvinas Lucha por la Vida, se enfrentó ante una toma de decisión crucial para la lucha: la participación o no de la contienda electoral por el municipio. Si bien se decidió la participación, esto marcó un nuevo quiebre para la asamblea, dado que no hubo consenso en relación a la elección del candidato y a la línea político partidaria que adoptarían. En consecuencia, una facción de los miembros de la asamblea se presentaron a la contienda elector por el partido político Patria Grande, en tanto que otros miembros decidieron conformar un partido político autónomo al que denominaron Malvinas Despierta. El resultado eleccionario, si bien no permitió que los miembros de la asamblea tomasen posesión del municipio, si logró consolidar a Malvinas Despierta como principal frente opositor.

No obstante lo señalado, nos parece interesante subrayar que más allá de los quiebres y las disputas al interior de la asamblea, esta supo mantener una estrategia de unidad de cara al objetivo común que sostenían: el NO a la instalación de Monsanto en Malvinas. Esta estrategia, según se desprende del relato de los vecinos, consistió, como mencionamos, en iniciar por acciones no disruptivas, para ganar legitimidad y luego poder disrumpir en el espacio público sin que esto significase una pérdida de dicha legitimidad. Además, la estrategia se organizó en diferentes frentes de lucha y con diferentes cabezas. Uno de nuestros entrevistados mencionaba:

“cuando ya no era posible mantener la unión, yo siempre decía: a vos te gusta esto, agarrate tu grupo y resistí por otro lado, tené tu estrategia, lo importante es que haya muchas cabezas. La idea de la asamblea sirve para un actor pero no para resistencia global, la resistencia global necesita muchas fuerzas y muchas cabezas”(Víctor, docente, 41 años).

La estrategia de múltiples cabezas posibilitó la autonomía de cada uno de los grupos en resistencia y complejizó el escenario de disputa. Es decir, no había un solo líder de la resistencia al que se pudiese atacar, amenazar, cooptar o acallar. Al ser múltiples los referentes, eran múltiples los repertorios de resistencia y los discursos que tanto el estado como Monsanto debían contrarrestar. Frente una lucha desigual, la estrategia de múltiples cabezas tendió a la igualdad de fuerzas, transformándose en la honda de David, y posibilitando vencer a una de las empresas más poderosas y con mayor lobby del agronegocio.

La resistencia que estamos analizando, al igual que variadas resistencias al modelo extractivo, no sólo ponen en evidencias asimetrías de poder, sino que también ponen de manifiesto profundas asimetrías en los procesos sociales de producción de las significaciones. En tal sentido, es interesante destacar que en estas luchas no sólo está en juego el NO a la instalación de determinada empresa o megaproyecto, sino que además, se ponen en juego diferentes lenguajes de valoración que pujan sentidos en torno a los medios y formas de vida.

En este marco, la Asamblea Malvinas Lucha por la Vida debió, en primer lugar, disputar discursivamente la subjetividad política de vecino que venía encarnando y construyendo. Esto es así ya que cualquier discurso que emerja como crítico o en oposición al modelo extractivo tenderá a ser descalificada tanto por el poder político, económico como mediático. Siguiendo a Foucault (1992), consideramos que este tipo de discursos descalificadores proliferan con el fin de vigilar la aparición de enunciados, y de todo lo que pueda encontrarse en ellos, que se considere violento, peligroso y batallador.

Lo que conduce, en términos de Angenot (2012), a reforzar la hegemonía discursiva que funciona como censura, dando cuenta de quién puede hablar, de qué y cómo puede hacerlo. Por tanto, estos discursos pretenden tensionar la subjetividad política de la asamblea y encuadrar su accionar en los márgenes de lo político. Al desplazar el actuar hacia los márgenes, la asamblea deja de considerarse un actor legítimo en conflicto. Un ejemplo de lo dicho puede sintetizarse en el siguiente relato: 
"Y esto de que, de que no somos nosotros, que somos diez tontos o diez locos, diez hippies que somos fundamentalistas es, palabras del intendente, si, literalmente. Que somos fundamentalistas, que nosotros no somos especialistas, que no somos vecinos de Malvinas” (Vanesa, estudiante, 23 años).

En segundo lugar, los vecinos construyeron una cadena articulatoria de sentido que potenció la identidad de su lucha. A partir de entender que la resistencia a la instalación de Monsanto en Malvinas Argentinas no puede ser comprendida en enclave del culto a lo silvestre o el evangelio de la ecoeficiencia (Martínez Alier, 2004), sino que debe ser abordada desde una perspectiva biocéntrica, nos es posible comprender que la cadena articulatoria de sentidos que fueron construyendo los vecinos se basó principalmente en los ejes vida y salud. Ambos ejes, presentes en el nombre de la asamblea y en una frase recurrentemente usada por los vecinos: el progreso que mata y contamina no es progreso, posibilitan pensar en los diversos lenguajes que se pusieron en puja y la forma en la que se fueron construyendo y disputando los roles en conflicto.

Así, nos encontramos con los vecinos, quienes al revalorizar la vida y la salud, significaban a Monsanto como portador de muerte y enfermedad. Por su parte, Monsanto, al referirse a los vecinos como fundamentalistas o violentos, buscaba no sólo desacreditar su accionar, sino significarse como moderado y pacífico, quitándose responsabilidad del conflicto. A su vez, procuraba (re)presentarse como portador de progreso para la comunidad, lo que colocaba a los vecinos en el rol de antiprogresistas. Esta construcción de sentido fue permanentemente disputada por los vecinos a partir de, por un lado, cuestionar de qué progreso hablaba la empresa, para quién era y a costas de qué era; por otro lado,de revalorizar otras formas de progreso alternativas a las que presentaba Monsanto.

A partir de lo señalado es posible evidenciar como las empresas multinacionales y, en la mayoría de los casos, los estados nación que alientan los grandes emprendimientos,parten de una racionalidad económicainstrumental, acorde con un vínculo antropocéntrico y utilitarista con la naturaleza, a fin de tomar posesión de un territorio, de naturalezas y subjetividades que, desde esta racionalidad, no son más que un lugar de sacrificio para el logro de su acumulación de capital. En contrapartida, los defensores de los territorios, naturalezas y subjetividades revalorizan un lenguaje que, al decir de Svampa y Viale, "ilustra el cruce innovador entre matrizindígeno-comunitaria, defensa del territorio y discurso ambientalista” (2014, p. 35), a partir de abrazar una racionalidad ambiental (Leff, 2004) que les posibilita concebirse como parte de la naturaleza y entablar vínculos plurales y diversos con ésta.

\section{Algunas reflexiones a modo de cierre}

La lucha de los vecinos de Malvinas Argentinas para que Monsanto no se instalase en su comunidad duró cuatro años. En este tiempo, los vecinos se transformaron en sujetos políticos y fueron capaces de disputar el poder hegemónico estatal y capitalista a partir de múltiples repertorios de resistencia. Es innegable, como planteábamos al comienzo de este escrito, que esta lucha se transformó en un ícono de las luchas socio-ambientales y territoriales de Argentina, dado que los vecinos no sólo se enfrentaron y frenaron a la empresa insignia del extractivismo agrícola, el patentamiento de semillas y material genético, sino que además pudieron hacerle frente a la transversalidad política y mediática que había por detrás.

Es menester reconocer, en el logro del objetivo propuesto, el éxito de la estrategia de múltiples cabezas que adoptó con el correr del tiempo la Asamblea. No obstante, nos cuestionamos por los costos que esa estrategia conllevó, dado que en los cuatro años de lucha hubo al menos tres quiebres significativos al interior de la Asamblea. Tampoco es posible negar, que parte del éxito estuvo sustentado en el apoyo y la presencia de los grupos anarquistas en el bloqueo permanente que se realizó a Monsantopor más de tres años. No obstante, también quisiéramos llamar la atención en relación a la conflictiva y dificultosa articulación entre estos grupos y la Asamblea y los problemas que esto generó al interior de la misma.

Finalmente, nos resulta llamativo el rumbo que adoptó la asamblea, la que prefirió transformarse en un partido político en vez de en un movimiento social consolidado en el tiempo más allá del logro del objetivo del NO a Monsanto. En este punto quisiéramos resaltar que, en la actualidad, Malvinas Despierta se alineó con el 
poder político hegemónico de la Provincia de Córdoba y logró en las elecciones del 2019 ganar la intendencia. Aspecto que es al menos llamativo, ya que fueron los funcionarios representantes de esta fuerza política a nivel provincial, los que apoyaron la instalación de Monsanto en la comunidad.

Pese a lo dicho, es imposible negar que la lucha en contra de la instalación de Monsanto en Malvinas Argentinas marcó un quiebre en la vida política de la comunidad. En la actualidad los habitantes de Malvinas Argentinas son capaces de disputar acciones y sentidos, de organizarse y de cuestionar aquellos órdenes establecidos que no se condicen con el interés común de la población. Por tanto, comprendemos que, si bien la asamblea no perduró en el tiempo más allá del conflicto, contribuyó a forjaruna dinámica de co-construcción democrática participativa que tiende a revalorizar los derechos sociales, ambientales y humanos. Y demostró que frente a las nuevas modalidades de producción de desigualdades generadas por el neocolonialismo-capitalistas-extractivo global, se alzó una voz de resistencia, que al igual que muchas otras voces en América Latina, constituyen manifestaciones de territorialidades y subjetividades que encarnan, construyen y deconstruyen acciones y discursos a partir del dolor de la expropiación. En consecuencia, el territorio, objeto de sacrificio y disputa, se resignifica, se reterritorializa y se transforma, gracias a la lucha, en un territorio de esperanza que permite alumbrar otras luchas y otros mundos posibles.

\section{Notas}

${ }^{1}$ El diario La voz del Interior, es el medio gráfico con mayor tirada en la provincia de Córdoba

${ }^{2}$ Concepto desarrollado por Jean Brunhes, geógrafo Francés, que implica “una modalidad peculiar de 'ocupación destructiva' del espacio por parte de la especie humana, que tiende a arrancarle materias minerales, vegetales o animales, sin idea ni medios de restitución” (Castro Herrera, 1994, pág. 27).

3 “una compleja y profunda transformación técnico-científica cuyo objetivo fue incrementar la producción agrícola por intermedio de mecanismos y manipulaciones técnico-científicas” (Taddei, 2013, p. 159).

${ }^{4}$ Creado durante el gobierno militar de 1956

5 Datos del Censo Nacional 2010. Recuperado de https://www.google.com.ar/ url?sa=t\&rct=j\&q=\&esrc=s\&source=web\&cd=1\&cad=rja\&uact=8\&ved=0ahUKEwif18yPivXLAhULj5AKHcDhBh4QFggcMAA\&url=http\%3A\%2F\% 2Festadistica.cba.gov.ar\%2FLinkClick.aspx\%3Ffileticket\%3D48RZHL7ihmQ\%253D\%26tabid\%3D617\%26language\%3DesAR\&usg=AFQjCNE_trAjpLKWUFf982lOTxfWG3iPsA\&sig2=O2H4aMgnQH7xb82qogH_Lg\&bvm=bv.118443451,d.Y2I el 04/04/2016

${ }^{6}$ Diario La Voz del Interior, edición digital del día 30/12/2010 http://www.lavoz.com.ar/ciudadanos/el-56-de-las-localidades-sufrepobreza-grave consultado el 5/04/2016

${ }^{7}$ Para más información se puede consultar: http://www.juicioalafumigacion.com.ar/

${ }^{8}$ Almuerzo en el Council de las Américas: Palabras de la Presidenta de la Nación(15/07/12) recuperado de http://www.casarosada.gob.ar/ informacion/archivo/25918-almuerzo-en-el-council-de-las-americas-palabras-de-la-presidenta-de-la-nacion consultado el 5/04/2016 Monsanto, comunicado de Prensa del 13/06/2012 http://www.monsanto.com/global/ar/noticias-y-opiniones/pages/20120613.aspx consultado el 5/04/2016

${ }^{9}$ Diario La Voz del Interior, edición digital del día 17/07/2012 http://www.lavoz.com.ar/noticias/negocios/monsanto-invertira-1600millones-cordoba-se-instalara-malvinas-argentinas Consultado el 7/04/2016

${ }^{10}$ Diario La Voz del Interior, edición digital del día 18/07/2012 http://www.lavoz.com.ar/noticias/negocios/industria-maiz-apuestacordoba consultado el 7/04/2016

${ }^{11}$ Diario La Voz del Interior, edición digital del día 10/07/2012 http://www.lavoz.com.ar/noticias/negocios/intendente-malvinas-argentinas-destaco-llegada-monsanto consultado el 7/04/2016

\section{Bibliografía}

Alimonda, H. (2006). Una nueva herencia en Comala. Apuntes sobre la ecología política latinoamericana y la tradición marxista. . En H. Alimonda, Los tormentos de la materia. Aportes para una ecología política latinoamericana (págs. 93-122). Buenos Aires, Argentina: CLACSO. 
(2011). La colonialidad de la naturaleza. Una aproximación a la Ecología Política latinoamericana. En H. Alimonda, La Naturaleza Colonizada. Ecología Política y Minería en América Latina (pp. 21-60). Buenos Aires, Argentina: Clacso.

Angenot, M. (2012). El discurso social. Los límites históricos de lo pensable y lo decible. Buenos Aires - Argentina: Siglo XXI.

Antonelli, M. A. (2010). Minería Transnacional y dispositivos de intervención en la cultura. La gestión del paradigma hegemónico de la "minería responsable y el desarrollo sustentable”. En M. Svampa, \& M. A. Antonelli, Minería Transnacional, narrativas del desarrollo y resistencias sociales (pp.51-101). Buenos Aires, Argentina: biblos.

Ávila Vázquez, M. (2013). El Chantaje social del Intendente Arzani y De la Sota en Malvinas Argentinas. Córdoba, Argentina: Red Universitaria de Ambiente y Salud - Médicos de Pueblos Fumigados.

Barri, F. y Wahren, J. (2010). "El modelo sojero de desarrollo en la Argentina: tensiones y conflictos en la era del neocolonialismo de los agronegocios y el cientificismo-tecnológico”, Realidad Económica (255), 43-65

Carrasco, A., Sánchez, N. y Tamagno, L. (2012).Modelo Agrícola e Impacto Socio-Ambiental en Argentina: Monocultivo y Agronegocios. La Plata, Argentina: AUGM Asociación de Universidades Grupo Montevideo y UNLP.

Castro Herrera, G. (1994). Los trabajos de ajuste y combate. Naturaleza y sociedad en la historia de América Latina . Bogotá, Colombia: Casa de las Américas-Colcultura .

de Sousa Santos, B. (1998). De la mano de Alicia. Lo social y lo político en la posmodernidad. Bogotá, Colombia: Siglo del Hombre Editores y Universidad de los Andes.

(2009). Epistemología del sur.Ciudad de México, México: Siglo XXI.

Escobar, A. (2007). La invención del tercer mundo. Construcción y deconstrucción del desarrollo.Caracas, Venezuela: Fundación Editorial el perro y la rana.

(2011). Ecología política de la globalidad y la diferencia. En H. Alimonda, La naturaleza colonizada. Ecología política y minería en América Latina (págs. 61-92). Buenos Aires, Argentina: CLACSO.

Foucault, M. (1992). El orden del discurso. Buenos Aires, Argentina: Tusquets Editores.

Giarraca, N. y Teubal, M. (2013).Actividades Extractivas en Expansión ¿Reprimarización de la economía Argentina?. Buenos Aires, Argentina: Antropofagia

Gras, C. y Hernández, V. (2013).Los pilares del modelo agrobusiness y sus estilos empresariales. En Gras, C. y Hernández, V.El agro como negocio. Producción, sociedad y territorios en la globalización. (pp. 17-48) Buenos Aires, Argentina: Biblos.

(2016). Radiografía del nuevo campo argentino. Del terrateniente al empresario transnacional. Buenos Aires, Argentina:Siglo veintiuno editores

Harvey, D. (2004). The New Imperialism: Accumulation by Despossession. The Socialist Register, 63-87.

Lander, E. (2011). La Colonialidad del Saber. Buenos Aires, Argentina: CICCUS.

Leff, E. (2004). Racionalidad ambiental. La reapropiación social de la naturaleza. Ciudad de México, México: Siglo XXI. 
(2006).La ecología política en América Latina. Un campo en construcción. En Alimonda, H. Los tormentos de la materia. Aportes para una ecología política latinoamericana, Buenos Aires, Argentina: CLACSO

Ley General del Ambiente, 25675 (El Senado y Cámara de Diputados de la Nación Argentina 27 de 11 de 2002).

Machado Aráoz, H. (2011). El auge de la minería transnacional en América Latina. De la ecología política del neoliberalismo a la anatomía política del colonialismo. En H. Alimonda, La naturaleza colonizada. Ecología política y minería en América Latina(págs. 135-180). Buenos Aires, Argentina: CICCUS-CLACSO.

Martínez Alier, J. (2004).El ecologismo de los pobres. Conflictos ambientales y lenguajes de valoración, Barcelona, España: Icaria/FLACSO

Merlino, A. (2012). Investigación cualitativa y análisis del discurso. Argumentación, sistemas de creencias y generación de tipologías en el estudio de la producción discursiva. Buenos Aires, Argentina: Biblos.

Municipalidad de Malvinas Argentinas. (2006). Malvinas Argentinas. El impulso de un pueblo joven que construye futuro. Córdoba, Argetina: Imprenta de Lotería de Córdoba S.E.

Polanyi, K. [1944] (2007).La gran transformación. Crítica del liberalismo económico. Quipu editorial

Seoane, J. (2013). Modelo extractivo y acumulación por despojo. En J. Seoane, E. Taddei, \& C. Algranati, Extractivismo, despojo y crisis climática. Desafíos para los movimientos sociales y los proyectos emancipatorios de Nuestra América (págs. 21-39). Buenos Aires, Argentina: El Colectivo.

Seoane, J., Taddei, E., y Algranati, C. (2013). Extractivismo, despojo y crisis climática. Desafío para los movimientos sociales y los proyectos emancipatorios de Nuestra América. Buenos Aires, Argentina: Herramienta - El colectivo.

Svampa, M. y Viale E. (2014).Maldesarrollo. La argentina del extractivismo y el despojo. Buenos Aires, Argentina: Katz

Taddei, E. (2013); “El agronegocio: de la república de la soja a los desiertos verdes”, en José Seoane, Clara Algranati y Emilio Taddei, Extractivismo, despojo y crisis climática. Desafíos para los movimientos sociales y los proyectos emancipatorios de Nuestra América. (pp. 157-182). Buenos Aires, Argentina: El Colectivo

(2016). Relegitimación de la gobernabilidad neoliberal y conflictos sociales en la Argetina y en Sudamérica. III Jornadas de Estudios de América Latina y el Caribe “América Latina: escenarios en disputa” (págs. 129). Buenos Aires, Argentina: IEALC - UBA.

Teubal, M. (1984). Internacionalización del capital y complejos agroindustriales: impactos sobre la agricultura latinoamericana.Investigación Económica, 43 (170), 129-159.

(2006). Expansión del modelo sojero en la Argentina. De la producción de alimentos a los commodities. Realidad Económica, 71-96.

Vasilachis de Gialdino, I. (2007). Estrategias de investigación cualitativa. Buenos Aires, Argentina: Gedisa.

Worster, D. (2008).Transformaciones de la tierra. Montevideo, Uruguay: CLAES 